WILEY-VCH

"This is the peer reviewed version of the following article: Angew. Chem. Int. Ed. 2016, 55, 11037-11040, which has been published in final form at DOI: 10.1002/anie.201603638|. This article may be used for non-commercial purposes in accordance with Wiley Terms and Conditions for Self-Archiving published at http://olabout.wiley.com/WileyCDA/Section/id-820227.html." 


\title{
Highly Efficient Catalytic Formation of (Z)-1,4-But-2-ene Diols using Water as a Nucleophile
}

\author{
Wusheng Guo, ${ }^{[a][b]}$ Luis Martínez-Rodríguez, ${ }^{[a][b]}$ Eddy Martin, ${ }^{[a]}$ Eduardo C. Escudero-Adán ${ }^{[a]}$ and Arjan \\ W. Kleij $\left.{ }^{*}[\mathrm{a}] \mathrm{c}\right]$
}

\begin{abstract}
The first general catalytic and highly stereo-selective formation of (Z)-1,4-but-2-ene diols is described from readily available and modular vinyl-substituted cyclic carbonate precursors using water as a nucleophilic reagent. These 1,4-diol scaffolds can be generally prepared in high yields and with ample scope in reaction partners using a simple synthetic protocol that does not require the presence of any additive or any special precaution unlike the stoichiometric approaches reported to date. Control experiments support the mechanistic view that hyper-conjugation within the catalytic intermediate after decarboxylation plays an imperative role to control the stereo-selective outcome of these reactions.
\end{abstract}

Diols are among the most ubiquitous scaffolds in chemistry being of eminent value to synthetic and polymer chemistry and typically encompassing a wide structural diversity. ${ }^{[1]}$ The stereoselective and enantio-selective preparation of 1,2-diols has undoubtedly received most of the attention of the synthetic community with the development of the hydrolytic kinetic resolution of epoxides ${ }^{[2]}$ and the asymmetric cis-dihydroxylation of alkenes ${ }^{[3]}$ representing important milestones in this area. As established for 1,3-diols, ${ }^{[1 \mathrm{a}]}$ diastereo-selective preparation of other diol scaffolds remains rewarding but persists to challenge synthetic chemists. In this respect, acyclic unsaturated (Z)-configured 1,4-diols have found important applications as transient scaffolds towards the stereocontrolled preparation of vinylcyclopropanes, ${ }^{[4]}$ vinyl glycinols ${ }^{[5]}$ and the formation of lactones. ${ }^{[6]} \mathrm{A}$ recent contribution from Hoveyda $^{[7]}$ has exposed further growth potential of these 1,4-diol synthons in catalytic and stereoselective cross-metathesis furnishing valuable acyclic (Z)-allylic alcohols.

Up to now, the limited amount of available strategies for (Z)1,4-but-2-ene diols synthesis have in common that they require stoichiometric chemistry and/or air-sensitive reagents such as DIBAL-H (diisobutylaluminum hydride). ${ }^{[4,5]}$ Despite the increasing incentive of $(Z)$-1,4-but-2-ene diols in synthetic chemistry, the quest towards an efficient and mild catalytic protocol focusing on such (substituted) 1,4-diol scaffolds still continues. ${ }^{[8]}$ Inspired by the dearth of catalytic solutions for the stereo-controlled

[a] Dr. W. Guo, L. Martinez, Dr. E. Martin, E. C. Escudero-Adán, Prof. Dr. A. W. Kleij, Institute of Chemical Research of Catalonia (ICIQ), the Barcelona Institute of Science and Technology, Av. Països Catalans 16, 43007 Tarragona, Spain

E-mail: akleii@iciq.es

[b] These authors contributed equally.

[c] Prof. Dr. A. W. Kleij

Catalan Institute of Research and Advanced Studies (ICREA), Pg Lluís Companys 23, 08010 Barcelona, Spain

Supporting information for this article is given via a link at the end of the document construction of substituted (Z)-but-2-ene diols, we anticipated the use of vinyl-substituted cyclic carbonates as key reaction partners. Previous success with these latter scaffolds demonstrated that decarboxylative functionalization with suitable electrophiles such as Michael acceptors is feasible under mild reaction conditions giving access to furans, ${ }^{[9 a]}$ tertiary vinylglycols ${ }^{[9 b]}$ and highly functional pyrrolidines. ${ }^{[9]}$ As an intermediate in these $\mathrm{Pd}$-mediated processes a zwitter-ionic structure was postulated (see Scheme 1). Conceptually, such a charged-separated structure should possess ambivalent reactivity, with the Pd-allyl fragment being highly electrophilic and amenable to react with (very) weak nucleophiles such as water. Examples of catalytic conversions that are based on the use of water as nucleophilic reagent are, however, extremely rare. ${ }^{[1,2,2,10]}$ A successful development of new catalytic methodology towards selective (Z)-but-2-ene diol formation by nucleophilic hydration of in situ formed allyl surrogates would provide a highly attractive new route towards these synthetically useful scaffolds. Here we disclose such a conceptually new and highly efficient approach for (Z)-but-2-ene diols that is based on a decarboxylative hydration of readily available vinyl-based cyclic carbonates under mild operating conditions (Scheme 1).

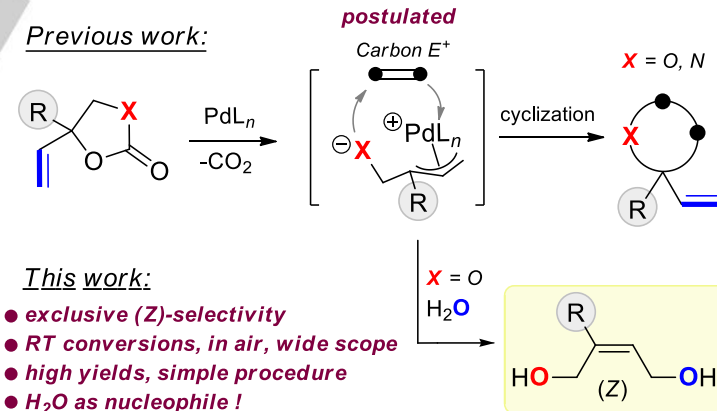

Scheme 1. A previously postulated zwitterionic Pd-allyl intermediate and current approach towards (Z)-1,4-but-2-ene diols using $\mathrm{H}_{2} \mathrm{O}$ as nucleophile.

The screening phase towards appropriate reaction conditions for the synthesis of unsaturated 1,4-diol compound 1 started off with the use of vinyl carbonate $\mathbf{A}$ and using various Pd precursors and phosphine ligands (Table 1). Various Pd precursors were tested including the well-known and reactive White catalyst. ${ }^{[11]} \mathrm{We}$ first screened various mono- and bidentate ligands (L1-L8) combined with this precursor using DMF as solvent. ${ }^{[12]}$ Whereas the use of mono-dentate phosphine ligands L1-L5 (entries 1-5) did not result in any observable formation, to our delight the presence of bidentate phosphines L6-L8 (entries 6-8) proved to be highly beneficial for the formation of the desired 1,4-but-2-ene diol 1 under ambient conditions (see also Table S1, Supporting 
Information). Moreover, ${ }^{1} \mathrm{H}$ NMR analysis supported the exclusive formation of the (Z)-configured product (Z/E >99:1). Further screening (entries 9-13) of other Pd precursors in the presence of L8 showed $\mathrm{Pd}(\mathrm{dba})_{2}$ and $\left[\mathrm{Pd}_{2}(\mathrm{dba})_{3} \cdot \mathrm{CHCl}_{3}\right] \quad(\mathrm{dba}=$ dibenzylideneacetone) to be competitive precursors, but to avoid any potential problem related to the stability of these $\mathrm{Pd}$ precursors we decided to continue with the air-stable White precursor. Other solvents than DMF were probed (entries 14-17) but these showed inferior yields of $\mathbf{1}$ underlining the crucial importance of the polarity of the medium.

Table 1. Optimization of conditions in the synthesis of (Z)-but-2ene diol 1 varying the $\mathrm{Pd}$ precursor, ligand $\mathbf{L}$ and solvent. ${ }^{[a]}$<smiles>C=CC1(c2ccccc2)COC(=O)O1</smiles><smiles>[R]c1ccccc1P(c1ccccc1[R])c1ccccc1CCC</smiles>

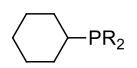

L3: $\mathrm{R}^{2}=\mathrm{Ph}$

L1: $\mathrm{R}^{1}=\mathrm{H}$ L4: $R^{2}=C y$<smiles>c1coc(P(c2ccco2)c2ccco2)c1</smiles>

L2: $\mathrm{R}^{1}=\mathrm{Me}$$$
\text { L5 }
$$

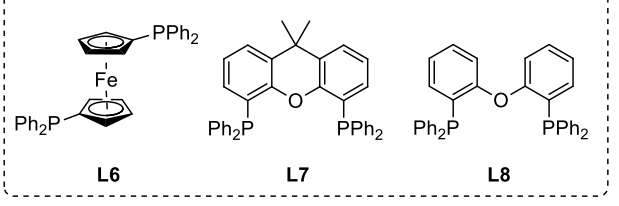

\begin{tabular}{|c|c|c|c|c|}
\hline Entry & Pd precursor & $\mathrm{L}$ & $\begin{array}{c}\text { Solvent } \\
{[1 \mathrm{M}]}\end{array}$ & $\begin{array}{c}\text { Yield }^{[\mathrm{b}][\mathrm{c}]} \\
{[\%]}\end{array}$ \\
\hline 1 & $\mathrm{Pd} /$ bis-sulfoxide & L1 & DMF & 0 \\
\hline 2 & $\mathrm{Pd} /$ bis-sulfoxide & L2 & DMF & 0 \\
\hline 3 & $\mathrm{Pd} /$ bis-sulfoxide & L3 & DMF & 0 \\
\hline 4 & $\mathrm{Pd} /$ bis-sulfoxide & L4 & DMF & 0 \\
\hline 5 & $\mathrm{Pd} /$ bis-sulfoxide & L5 & DMF & 0 \\
\hline 6 & $\mathrm{Pd} /$ bis-sulfoxide & L6 & DMF & 90 \\
\hline 7 & $\mathrm{Pd} /$ bis-sulfoxide & L7 & DMF & 95 \\
\hline 8 & $\mathrm{Pd} /$ bis-sulfoxide & L8 & DMF & 98 \\
\hline 9 & {$\left[\mathrm{Pd}_{2}(\mathrm{dba})_{3}\right] \cdot \mathrm{CHCl}_{3}$} & L8 & DMF & 97 \\
\hline 10 & $\mathrm{Pd}(\mathrm{dba})_{2}$ & L8 & DMF & 99 \\
\hline 11 & $\mathrm{Pd}(\mathrm{OAc})_{2}$ & L8 & DMF & 94 \\
\hline 12 & $\mathrm{Pd} / \mathrm{C}$ & L8 & DMF & 0 \\
\hline 13 & $\mathrm{Pd}\left(\mathrm{PPh}_{3}\right)_{2} \mathrm{Cl}_{2}$ & L8 & DMF & 70 \\
\hline 14 & $\mathrm{Pd} /$ bis-sulfoxide & L8 & $\mathrm{CH}_{3} \mathrm{CN}$ & 40 \\
\hline 15 & $\mathrm{Pd} /$ bis-sulfoxide & L8 & $\mathrm{MeOH}$ & $<1$ \\
\hline 16 & $\mathrm{Pd} /$ bis-sulfoxide & L8 & $\mathrm{CH}_{2} \mathrm{Cl}_{2}$ & 0 \\
\hline 17 & $\mathrm{Pd} /$ bis-sulfoxide & L8 & THF & 0 \\
\hline
\end{tabular}

[a] Reaction conditions: $0.20 \mathrm{mmol}$ of carbonate, $0.20 \mathrm{~mL}$ of solvent, $\mathrm{rt}$; [b] NMR yield using toluene as internal standard, see Supporting Information for details. [c] In all cases the Z/E ratio was $>99: 1$ as determined by ${ }^{1} \mathrm{H}$ NMR.

The optimized conditions reported in entry 8 of Table 1 were then used to investigate the product scope in detail (Figure 1). The R-groups of the vinyl carbonate reagent was systematically varied (for their preparation, see Supporting Information) and provided an entry into a series of substituted (Z)-but-2-ene diols 1-28. In most cases excellent isolated yields (up to 98\%) and selectivity (>99:1) towards the $(Z)$ isomer were noted. This userfriendly procedure does not require any additive and can be operated in air at ambient temperature. The introduction of various aryl groups in the olefinic unit is tolerated including para-, meta- and ortho-substituted (di)halo-aryls $(2,3,7,18,19,20,21$, 23 and 24), benzoic ester (9) and even thioether (12) groups. The use of 2- and 3-furyl, thiophene- and 3-pyridyl-substituted cyclic carbonates smoothly leads to (Z)-1,4-diols 13-16 in high yield despite the potential of the heteroatoms to coordinate and deactivate the Pd-catalyst.
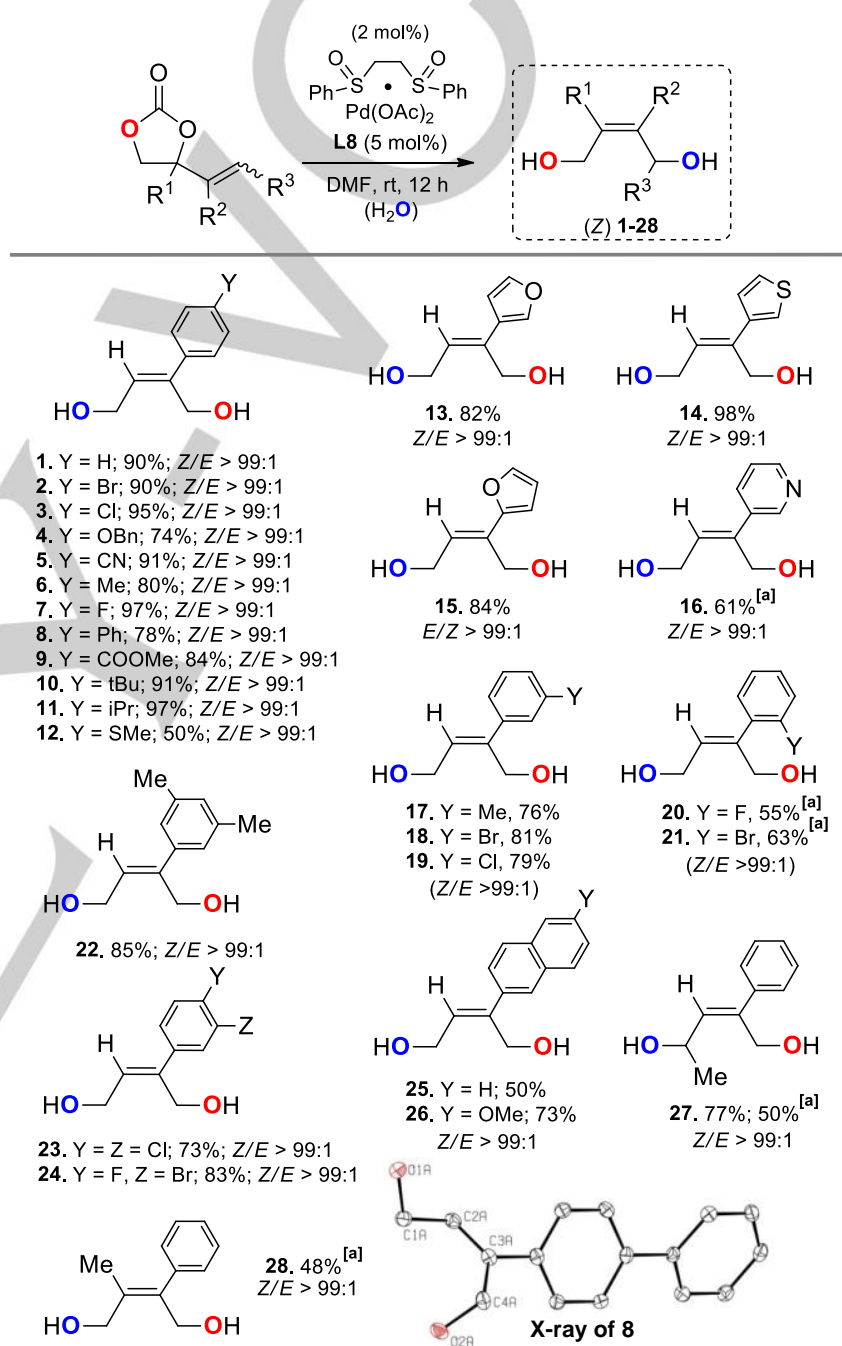

Figure 1. Product scope in the Pd-mediated formation of $(Z)$-but-2-ene diols 1 28. Substrate amounts used: carbonate $(0.20 \mathrm{mmol})$, DMF $(0.20 \mathrm{~mL})$. The $Z / E$ ratios were determined by ${ }^{1} \mathrm{H}$ NMR spectroscopy $\left(\mathrm{CDCl}_{3}\right)$. Although following the same stereo-chemical formation pathway, compound 15 has formally an $(E)$ configuration. [a] Using $5 \mathrm{~mol} \%$ of Pd precursor and $10 \mathrm{~mol} \%$ of $\mathbf{L} 8,60^{\circ} \mathrm{C}, 200$ $\mu \mathrm{L}$ DMF, $60 \mu \mathrm{L} \mathrm{H}_{2} \mathrm{O}$.

Interestingly, the presence of other substitution patterns is also allowed producing an $\alpha$-functionalized diol (27) and a tetrasubstituted olefin derivative (28). Generally, in order to prepare these latter compounds with more elaborate substitutions and 
those incorporating ortho-functionalized aryl groups (cf., 20 and 21) and 3-pyridyl based 16 a higher reaction temperature and additional water in the medium was required; for these more challenging conversions also a higher amount of $\mathrm{Pd}$ catalyst (5 mol\%) was necessary. The $(Z)$ configuration was deduced from $1 \mathrm{D}$ and 2D NMR analysis, whereas in the case of 8 further evidence for the preferred stereo-isomer formation was obtained from X-ray diffraction studies (Figure 1). ${ }^{[13]}$
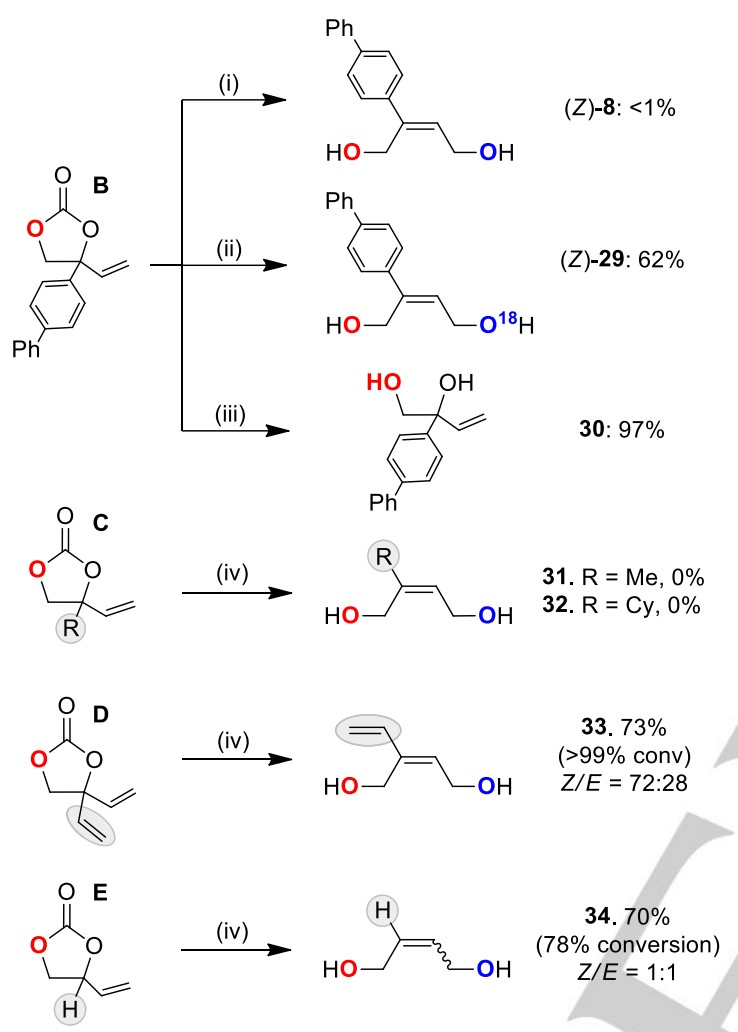

Scheme 2. Control experiments using vinyl carbonates B-E as substrates under different conditions: (i) anhydrous DMF $(0.2 \mathrm{~mL})$, White catalyst $(2.0$ mol\%), L8 (5.0 mol\%), rt, $12 \mathrm{~h}$; (ii) anhydrous DMF/ $\mathrm{H}_{2} \mathrm{O}^{18}(0.2 \mathrm{~mL} ; 9: 1)$, White catalyst (2.0 mol\%), L8 (5.0 mol\%), rt, 12 h; (iii) DMF/ $\mathrm{H}_{2} \mathrm{O}, \mathrm{NaOH}(5 \mathrm{eq}), \mathrm{rt}, 8 \mathrm{~h}$. (iv) conditions as under (i) using commercial DMF.

Intrigued by the highly stereo-selective nature of these conversions and in order to gain mechanistic insight, we performed a series of control experiments. Vinyl carbonate B (Scheme 2) was subjected to the same reaction conditions as used for 1-28 using anhydrous DMF; no conversion to diol (Z)-8 could be noted. Using a combination of anhydrous DMF with ${ }^{18} \mathrm{O}$ labelled water $(9: 1 \mathrm{v} / \mathrm{v})$ and treatment of vinyl carbonate $\mathbf{B}$ under these conditions afforded the labelled diol (Z)-29 in 62\% yield: these combined results support the key role of water in the stereoselective formation of the 1,4-diols. Further to this, when carbonate $\mathbf{B}$ is treated with $\mathrm{H}_{2} \mathrm{O}$ under basic conditions in the absence of $\mathrm{Pd}$ catalyst the 1,2-diol $\mathbf{3 0}$ is produced that results from the hydrolysis of the carbonate unit. ${ }^{[3 c, 14]}$ Therefore, the presence of a suitable $\mathrm{Pd}$ catalyst is essential to produce the 1,4diol products. In order to examine whether other vinyl-substituted carbonates (i.e., $\mathbf{C}-\mathbf{E}$ ) would equally convert to their corresponding (Z)-but-2-ene diols, the synthesis of 31-34 was attempted under the optimized reaction conditions. When alkylsubstituted carbonates were probed $(\mathbf{C} ; \mathrm{R}=$ alkyl) no conversion to the targeted diols 31 and 32 could be observed up to $60^{\circ} \mathrm{C}$. Interestingly, diol $\mathbf{3 3}$ derived from carbonate $\mathbf{D}$ that incorporates an additional vinyl substituent was obtained in $74 \%$ yield as a $72: 28$ mixture of both $(Z)$ and $(E)$ isomers. When carbonate $\mathbf{E}$ was employed the corresponding diol $34(Z / E=1: 1)$ was obtained under even lower stereo-control.

From the results presented in Scheme 2 a mechanistic rationale is proposed taking the previously postulated zwitter-ionic $\mathrm{Pd}$-allyl intermediate $\mathrm{I}^{\left[{ }^{[9]}\right.}$ as starting point (Scheme 3). Equilibration of $\eta^{3}$-allyl-Pd species $\mathbf{I}$ to $\eta^{1}$-palladacyclic intermediate $\mathbf{I I}$ is electronically biased as the presence of an aryl/vinyl substituent allows for hyper-conjugation of the double bond: this in turn controls the $(Z)$ configuration of the palladacycle and thus the stereo-control towards the 1,4-diol product. In turn, the lack of reactivity towards diol formation when $\mathrm{R}$ is an alkyl group (cf., 31 and 32; scheme 2) is explained by a larger charge-delocalization in intermediate I onto which nucleophilic attack by water is disfavored for electronic reasons. Thus, clearly electron-donating groups are unable to mediate the formation of intermediate II and no conversion is observed as indeed noted experimentally.

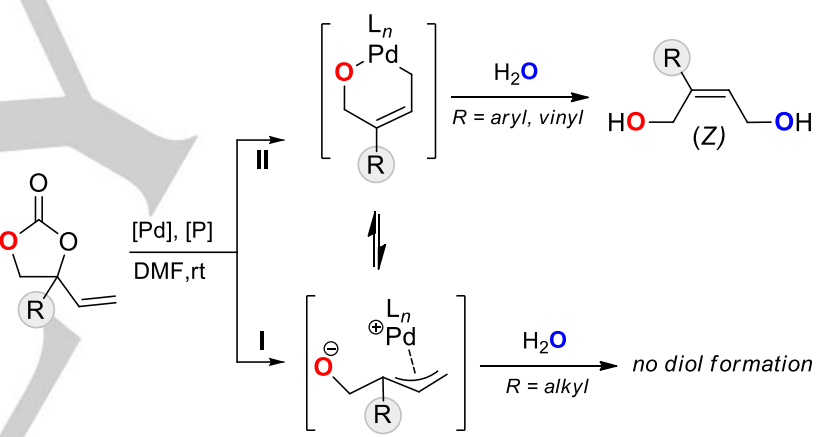

Scheme 3. Proposed mechanistic manifolds related to the Pd intermediates formed after decarboxylation.

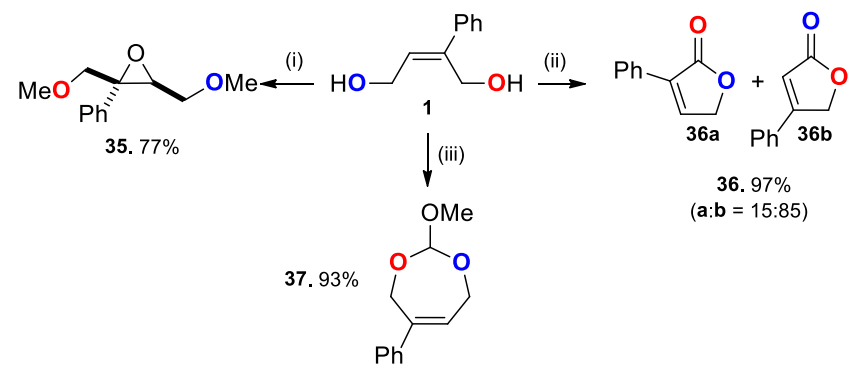

Scheme 4. Examples of post-use of (Z)-1,4-but-2-ene diol 1 in the synthesis of other interesting scaffolds (35-37). Conditions/reagents used: (i) $\mathrm{NaH}$ (3 eq.), Mel (4 eq.), DMF, rt; then $m$-CPBA (1.1 eq.), DCM, rt, $18 \mathrm{~h}$; (ii) Cul (5 mol\%), 2,2'-bipy (5 mol\%), 9-azabicyclo[3.3.1]nonane $N$-oxyl (1 mol\%), $N$-methyl imidazole (10 mol\%), ACN, rt, $3 \mathrm{~h}$; (iii) Camphorsulfonic acid (1 mol\%), trimethyl orthoformate (2 eq.), DCM, rt, $5 \mathrm{~h}$. 
In the case of the non-substituted carbonate $\mathbf{E}$ (Scheme 2), relatively slower conversion towards diol product is observed. The low $Z / E$ ratio of this latter conversion is the result of a nonstereospecific nucleophilic attack governed by steric rather than electronic considerations.

Finally, the post-modification potential of these (Z)-1,4-but-2ene diols was investigated using 1 as starting material (Scheme 4). Simple oxidation of the double bond (after alcohol protection) in 1 by meta-chloroperoxybenzoic acid afforded $\mathbf{3 5}$ as a single diastereo-isomer in $77 \%$ yield. Oxidative lactonization of 1 using a radical initiator (9-azabicyclo[3.3.1]nonane $\mathrm{N}$-oxyl) under $\mathrm{Cu}$ catalysis in the presence of $\mathrm{N}$-methyl-imidazole produced the lactone 36 in $97 \%$ yield. ${ }^{[6]}$ The cyclic ortho-ester 37 was prepared by combining 1 with trimethyl orthoformate ${ }^{[4]}$ under acid catalysis providing a well-known protection of this diol useful in synthetic chemistry. ${ }^{[15]}$

In summary, we here describe a user-friendly, highly mild and stereo-selective methodology towards the formation of synthetically useful (Z)-1,4-but-2-ene diols in high yield and under exclusive stereo-control. This procedure utilizes readily available and modular vinyl-based cyclic carbonates and simple water as reactants, can be operated in air and does not require any additive. Such privileged conditions may greatly advance the use of these diol synthons in preparative chemistry as demonstrated herein.

\section{Acknowledgements}

We thank ICIQ, ICREA, and the Spanish Ministerio de Economía y Competitividad (MINECO) through project CTQ-2014-60419-R, and the Severo Ochoa Excellence Accreditation 2014-2018 through project SEV-2013-0319. Dr. Noemí Cabello, Sofía Arnal, and Vanessa Martínez are acknowledged for the mass analyses. WG thanks the Cellex foundation for funding of a postdoctoral fellowship.

Keywords: decarboxylative functionalization $\bullet$ homogeneous catalysis $\cdot$ palladium $\cdot$ stereoselectivity $\bullet(Z)-1,4$-but-2-ene diols

[1] a) E. Bode, M. Wolberg, M. Müller, Synthesis 2006, 557-558; b) H. C. Kolb, M. S. VanNieuwenhuize, K. B. Sharpless, Chem. Rev. 1994, 94, 2483-2547; c) H. R. Kricheldorf, J. Macromol. Sci., Part C: Polym. Rev. 1997, 37, 599-631; d) C. J. R. Bataille, T. J. Donohoe, Chem. Soc. Rev. 2011, 40, 114-128; Use of diols for polyurethane preparations: e) H.-W Engels, H.-G. Pirkl, R. Albers, R. W. Albach, J. Krause, A. Hoffmann, H. Casselmann, J. Dormish, Angew. Chem. Int. Ed. 2013, 52, 9422-9441; In hydrolytic kinetic resolution: f) E. N. Jacobsen, Acc. Chem. Res. 2000 33, 421-431.
[2] M. Tokunaga, J. F. Larrow, F. Kakiuchi, E. N. Jacobsen, Science 1997 277, 936-938

[3] a) E. N. Jacobsen, I. Marko, W. S. Mungall, G. Schroeder, K. B Sharpless, J. Am. Chem. Soc. 1988, 110, 1968-1970; b) H. C. Kolb, P G. Anderson, K. B. Sharpless, J. Am. Chem. Soc. 1994, 116, 1278-1291. For a recent diastereo-selective approach towards syn-diols from cyclic carbonate precursors see: c) V. Laserna, G. Fiorani, C. J. Whiteoak, E. Martin, E. Escudero-Adán, A. W. Kleij, Angew. Chem. Int. Ed. 2014, 53 10416-10419.

[4] D. Craig, S. J. Gore, M. I. Lansdell, S. E. Lewis, A. V. W. Mayweg, A. J. P. White, Chem. Commun. 2010, 46, 4991-4993.

[5] K. Klimovica, L. Grigorjeva, A. Maleckis, J. Popelis, A. Jirgensons, Synlett. 2011, 2849-2851.

[6] X. Xie, S. S. Stahl, J. Am. Chem. Soc. 2015, 137, 3767-3770.

[7] M. J. Koh, R. K. M. Khan, S. Torker, M. Yu, M. S. Mikus, A. H. Hoveyda, Nature 2015, 517, 181-186.

[8] The only known catalytic method towards (Z)-but-2-ene diols (only 1 example) is based on the Pd-mediated hydroarylation of alkynes using arylboronic acids at $80^{\circ} \mathrm{C}$ in 1,4-dioxane, see: a) C. H. Oh, H. H. Jung, K. S. Kim, N. Kim, Angew. Chem. Int. Ed. 2003, 42, 805-808; b) A. K. Gupta, K. S. Kim; C. H. Oh, Synlett. 2005, 457-460.

[9] a) A. Khan, L. Yang, J. Xu, L. Y. Jin, Y. J. Zhang, Angew. Chem. Int. Ed. 2014, 53, 11257-11260; b) A. Khan, R. Zheng, Y. Kan, J. Ye, J. Xing, Y J. Zhang, Angew. Chem. Int. Ed. 2014, 53, 6439-6442; c) K. Ohmatsu, N. Imagawa, T. Ooi, Nat. Chem. 2014, 6, 47-51.

[10] a) G. Dong, P. Teo, Z. K. Wickens, R. H. Grubbs, Science 2011, 333 1609-1612; b) Q.-K. Kang, L. Wang, Q.-J. Liu, J.-F. Li, Y. Tang. J. Am Chem. Soc. 2015, 137, 14594-14597; Recently Sanford reported the in situ nucleophilic substitution of an alkyl chloride by water in the siteselective $\mathrm{C}-\mathrm{H}$ oxidation of amines at $150^{\circ} \mathrm{C}$, see: c) M. Lee, M. S. Sanford, J. Am. Chem. Soc. 2015, 137, 12796-12799. For related allylic hydroxylation see: d) B. J. Lüssem, H. J. Gais, J. Am. Chem. Soc. 2003, 125, 6066-6067; e) N. Kanbayashi, K. Onitsuka, Angew. Chem. Int. Ed. 2011, 50, 5197-5199; f) M. Gärtner, S. Mader, K. Seehafer, G. Helmchen, J. Am. Chem. Soc. 2011, 133, 2072-2075.

[11] The White catalyst is a bis-sulfoxide ligated $\mathrm{Pd}(\mathrm{OAc})_{2}$ precursor that has shown high potential in various allylic conversions, see for instance: a C. C. Pattillo, I. I. Strambeanu, P. Calleja, N. A. Vermeulen, T. Mizuno, M. C. White, J. Am. Chem. Soc. 2016, 138, 1265-1272; b) E. M. Stang, M. C. White, Nat. Chem. 2009, 1, 547-551.

[12] Note that if larger excess of $\mathrm{H}_{2} \mathrm{O}$ was used, the reaction was completely shut down.

[13] For more details see: CCDC-1465246.

[14] Simple hydrolysis of cyclic carbonates towards 1,2-diols has been welldocumented, see for instance: a) P. Le Gendre, T. Braun, C. Bruneau, P. H. Dixneuf, J. Org. Chem. 1996, 61, 8453-8455; b) C. Beattie, M. North, P. Villuendas, C. Young, J. Org. Chem. 2013, 78, 419-426; c) S. Sarel, I. Levin, L. A. Pohoryles, J. Chem. Soc. 1960, 3079-3082. See also reference $3 c$.

[15] a) M. Sekine, T, Hata, J. Am. Chem. Soc. 1983, 105, 2044-2049; b) J. J. Bozell, D. Miller, B. R. Hames, C.Loveless, J. Org. Chem. 2001, 66, 3084-3089. 


\section{Entry for the Table of Contents}

\section{COMMUNICATION}

A highly efficient and stereoselective Pd-mediated synthesis of substituted ( $Z$ )1,4-diols is described using allyl surrogates derived from vinyl cyclic carbonates. The methodology is characterized by its operational simplicity, high yields and stereo-control using water as a nucleophilic reagent. Control experiments support the view that hyperconjugation plays an imperative role in these stereospecific conversions.

Wusheng Guo, Luis Martínez-

Rodríguez, Eddy Martin, Eduardo

C. Escudero-Adán and Arjan W. Kleij*

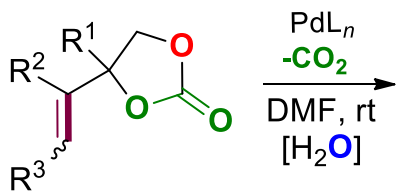

- Z/E typically >99:1

- $r t$, open to air, good scope

- 29 examples, high yields up to $98 \%$

- $\mathrm{H}_{2} \mathrm{O}$ as nucleophile !
Highly Efficient Catalytic Formation of (Z)-1,4-But-2-ene Diols using Water as a Nucleophile 